\title{
A educação matemática e a construção do número pela criança, mediada pela tecnologia digital.
}

\author{
Luís de França Ferreira ${ }^{1}$, Ana Cristina Rangel ${ }^{2}$, Magda Bercht ${ }^{3}$
}

RESUMO

Os artefatos digitais exercem na atualidade uma influência decisiva na atividade e no desenvolvimento humano. O número de pesquisas sobre o aprendizado com artefatos digitais, através da ação instrumentalizada, tem aumentado consideravelmente nestes últimos anos. Este artigo apresenta situações de aprendizagem na educação matemática, apoiadas no uso de objetos de aprendizagem baseados em computação gráfica, simulações digitais e jogos educativos, favorecedoras da construção do conhecimento pela criança.

\section{PALAVRAS CHAVES}

Educação matemática, Construção do número na criança, Piaget, Tecnologia digital Objetos de aprendizado.

\begin{abstract}
The digital devices exert in the present time a decisive influence in the activity and the human development. The number of research about learning with digital devices, through the action with instruments, has increased in these last years. This article presents learning situations in mathematical education, embebed in a learning object environment based on graphical computation, digital simulations and educative games. This situation is used to support the child's construction of the knowledge.
\end{abstract}

\section{KEYWORDS}

Mathematics education, Child's number construction, Piaget, Digital technology, Learning objects.

\footnotetext{
${ }^{1}$ Doutor em Informática na Educação (PPGIE--UFRGS), Professor do Centro Universitário Ritter dos Reis, Professor do Instituto de Informática da UFRGS, franca@ritterdosreis.br

${ }^{2}$ Mestre em Educação (PPGEDu), Professora do Centro Universitário Ritter dos Reis, rangelcris@yahoo.com.br

${ }^{3}$ Doutora em Ciência da Computação (PPGC-UFRGS), Professora do Pós-graduação em Informática na Educação, e no Instituto de Informática da UFRGS, bercht@inf.ufrgs.br

V.3 ํo 1, Maio, 2005
} 


\section{- Introdução}

Os artefatos digitais exercem na atualidade uma influência decisiva na atividade e no desenvolvimento humano. O número de pesquisas sobre o aprendizado com artefatos digitais, através da ação instrumentalizada, tem aumentado consideravelmente nestes últimos anos. As questões que se apresentam nesse campo, e que precisam ser respondidas, estão relacionadas ao "o quê", ao "como" e ao "quanto" se aprende na ação instrumentalizada, quando usamos estes artefatos. As respostas a estas questões passam necessariamente pelo estudo do processo no qual as ações se transformam em noções e operações, ou seja, o estudo das características das interações entre as formas práticas do conhecimento e do pensamento. A prática do uso intensivo de tecnologia para criar ambientes que proporcionem melhores condições para a aquisição e construção do conhecimento vem sofrendo uma incrível expansão. $\mathrm{O}$ desenvolvimento do potencial das tecnologias digitais a serviço do ensino é uma das aspiração de inúmeros programas de fomento à pesquisa e instituições voltadas à educação. $\mathrm{O}$ uso da tecnologia está possibilitando realização de experiências para além da noção popular de "sala de aula" e, sem dúvida nenhuma, os benefícios obtidos até agora com esta prática parecem promissores. Os diversos problemas que no entanto emergiram, não apontam para um arrefecimento nesta expansão. Com certeza, os esforços de pesquisa que se fazem necessários, encontrarão soluções para eles.

A construção de objetos de aprendizagem baseados em computação gráfica, simulações digitais, jogos educativos e realidade virtual na utilização em atividades educativas proporcionarão condições promissoras para a investigação dos efeitos da mediação digital sobre o processo de construção do conhecimento matemático da criança.

\section{- Abordagem teórica}

\subsection{Sobre a construção do conhecimento e a aprendizagem humana}

Inúmeros estudos importantes foram feitos por diversos pesquisadores tais como Lev Vigotsky, David Ausubel, Alexandr Luria, Wallon, entre outros, sobre como o homem aprende. Entretanto, sob o nosso ponto de vista, Jean Piaget e seus colaboradores são os autores da maior, mais profunda e fecunda obra sobre a gênese do conhecimento humano. Contribuições ricas e importantes também foram feitas por Maturana e Damásio, entre outros.

Para Piaget, somente alguns reflexos são inatos e o conhecimento é construído a partir da ação do sujeito sobre o objeto. "As ações realizadas pelo sujeito constituem a substância ou a matéria prima de toda a adaptação intelectual e perceptual." (FLAVELL, 1996, p. 81). Todo ser vivo, ao interagir com o meio, através de processos adaptativos, se transforma, organizando-se e adaptando-se.

A adaptação constitui-se de duas funções distintas, porém indissolúveis: Assimilação e Acomodação.

Por Assimilação entende-se a incorporação de um elemento exterior (objeto, acontecimento, etc) em um esquema sensório-motor ou conceitual do sujeito e de um esquema em um sistema de esquemas (PIAGET, 1977, p. 16). Os esquemas permitem dar significação ao objeto que, ao assimilá-lo, vão se diferenciando através de acomodações. Esquema é o que, em uma ação, é transponível, generalizável ou diferenciável de uma situação à seguinte, ou seja, o que há de comum nas diversas repetições ou aplicações da mesma ação (PIAGET, 1996, p 16). 
Acomodação (por analogia com os "acomodatos" biológicos) é toda modificação dos esquemas de assimilação sob influência de situações exteriores (meio) aos quais se aplicam (PIAGET, 1996, p 18). Mas, assim como não há assimilação sem acomodações (anteriores ou atuais), assim também não há acomodação sem assimilação. Isto significa que o meio não provoca simplesmente o registro de impressões ou a formação de cópias, mas desencadeia ajustamentos ativos no sujeito. É por isso que só falamos em "acomodação" subentendendo "acomodação de esquemas de assimilação". Desta forma, acomodar é a necessidade que a assimilação tem, ao considerar as particularidades próprias dos elementos a assimilar.

A adaptação ocorre, então, quando há equilíbrio entre assimilação e acomodação. Estas funções também se aplicam às estruturas mentais, que são o resultado da reorganização dos esquemas e servem de base para a construção de novas estruturas em nível mais elevado, que vão se desenvolvendo em quantidade e qualidade. Os estudos de Piaget sobre a inteligência apontam para uma correspondência entre as estruturas mentais elementares em desenvolvimento na criança e as estruturas - mães das Matemáticas enquanto Ciência.

Para Rangel, "o edifício da Matemática repousa sobre estruturas e estas correspondem às da própria inteligência. Nesta perspectiva, a Educação Matemática precisaria estar comprometida com o desenvolvimento progressivo e parcialmente espontâneo destas estruturas operatórias do pensamento infantil" (RANGEL, 1992, p. 21).

O conhecimento matemático e, conseqüentemente, o número, não são possíveis de serem aprendidos diretamente dos objetos materiais, por abstração das propriedades observáveis, tão pouco são aprendidos das abstrações das propriedades das ações exercidas materialmente sobre os objetos. A experiência lógico-matemática, diferentemente da experiência física, dirige-se às propriedades das ações, das transformações e de suas coordenações. A criança abstrai o número das propriedades que a sua ação introduz nos objetos, ou seja das coordenações que ligam suas ações. Assim, as ações que geram os conceitos matemáticos e, portanto, o número não se vinculam exclusivamente aos dados perceptivos materiais, mas apóiam-se no simbolismo, nas imagens mentais, ou seja, são ações também imagéticas: relações e, posteriormente, operações (quando as ações imagéticas adquirem a propriedade de se coordenarem reciprocamente, tornando-se reversíveis).

Uma questão relativa à aprendizagem inicial da matemática, diz respeito à indiferenciação dos pequenos sobre o caráter cardinal e ordinal do número. Quando já conseguem realizar suas contagens enumerando os objetos: um, dois, três, quatro, cinco..., o fazem como se estivessem atribuindo nomes a cada objeto da série e , assim "cinco", para eles, corresponderá ao $5^{\circ}$ elemento contado e não a todos os objetos da coleção. A origem do número, segundo Piaget, não está na contagem, mas na necessidade de quantificar coleções pela correspondência biunívoca e recíproca (um para cada um), onde a contagem passa a ser um recurso útil no acabamento desse processo, porém ainda inicialmente sem significação cardinal.

Além das questões relativas ao significado numérico, o educador precisa compreender que a Matemática é construída em práticas sociais, cuja comunicação se estrutura através da linguagem não só oral, mas escrita. Os signos numéricos explicitam diferentes funções nas relações sociais.

Numa abordagem menos complexa e carregada de sentido ao cotidiano dos pequenos, os signos evocam significações "nominais": é o indicador do canal preferido da televisão, ou o número da camiseta do "melhor" jogador de futebol... Mais adiante, explicitam significações ordinais e é assim, por exemplo, que uma criança "conta" os números do relógio, ou do calendário para pesquisar como se registra o cinco: "um" (1); 
"dois" (2); "três" (3); "quatro" (4); cinco (5). É interagindo com os signos numéricos em práticas sociais que remetem a significação nominal, ou cardinal, e tendo postulado a diferenciação entre o caráter cardinal e ordinal do número, em seus esforços de quantificação, recorrendo à contagem, que uma criança conceberá o uso do registro do signo numérico como o cardinal de uma coleção. Neste caso, possuiria esquemas conceituais suficientes para corresponder o signo " 5 " a um conjunto com cinco objetos.

Essas questões não estão suficientemente claras aos educadores que propõem intervenções em concepções epistemológicas de natureza empirista, apelando para o treinamento e a repetição de respostas, acreditando que de tanto contar e escrever, as crianças aprenderão o número. Pesquisas que investigam a gênese do conhecimento e as possibilidades de intervenção do meio educativo favorecedoras da construção do conhecimento pelas crianças, através de diferentes recursos lúdicos e ambientes interativos, são necessárias para fomentar a formação dos educadores e a qualificação da ação pedagógica comprometida com a educação na escola inclusiva.

\subsection{Sobre objetos de aprendizagem}

O uso da tecnologia como um agente de mudança trouxe inúmeros desafios, entre eles está a implementação de técnicas que possibilitem formas de projetar, desenvolver e distribuir material educacional para todos os que quiserem aprender. Uma tecnologia voltada para a educação, chamada "objetos de aprendizagem", que pode ser definido como "qualquer recurso digital que possa ser reutilizado e ajude na aprendizagem", tem se mostrado robusta, prática, econômica e forte candidata a liderar as alternativas de escolha para esta área, devido ao seu potencial de reusabilidade, generalidade, adaptabilidade e escalabilidade.

\section{- Sobre o experimento}

Neste experimento se propõe uma intervenção lúdica para crianças da idade pré escolar, propositiva à construção do número e à aprendizagem da leitura e da escrita dos signos numéricos. O experimento permite níveis diferenciados de intervenções, que têm como pressupostos os estudos psicogenéticos. A quantificação numérica é solicitada pelo apoio na correspondência biunívoca e recíproca: um cachorrinho para cada casa, ou um ossinho para cada cachorrinho. Assim, a criança é encorajada a estabelecer a correspondência ordinal entre os elementos das duas coleções, acrescentando os cachorrinhos, ou o pote com ossos, um a um às suas casas, pela correspondência entre os registros numéricos. Os signos numéricos são apresentados no experimento, não com a significação cardinal, que exige níveis de conceituação mais elaborados acerca do número, mas com significação nominal e/ou ordinal, indicando o cachorro que corresponderá a cada casa que está disposta ordenadamente na paisagem.

\subsection{Título do experimento}

CACHORRINHOS ENUMERADOS

\subsection{Objetivos do experimento}


- Estabelecer a correspondência biunívoca e recíproca entre os objetos de duas coleções, respeitando a ordem numérica proposta;

- Ler os signos numéricos, atribuindo-lhes significações nominais e ordinais;

- Atentar, para a localização espacial de objetos, exercitando a memória visual;

- Respeitar regras do jogo, transpondo a atividade lúdica para o plano virtual, aprendendo os comandos necessários da tecnologia, para a realização da atividade.

\subsection{Elementos do experimento}

O experimento contém os seguintes elementos (todos eles imagens simuladas no computador):

- Um dado ("sorteador” de números);

- um conjunto de casinhas,

- um conjunto de imagens de pequenos cachorros e

- três amigos virtuais: um menino moreno, uma menina em cadeira de rodas, e um menino loiro.

\subsection{Descrição e regras do experimento}

\section{$1^{\text {a }}$ intervenção: Jogo do Bingo}

O jogo inicia com a apresentação de três amigos virtuais: Um menino moreno, uma menina em cadeira de rodas, e um menino loiro. A criança escolhe com qual amigo irá jogar e ele combina (apresenta) as regras do jogo oralmente (as regras também são apresentadas através da linguagem de sinais).

$\mathrm{Na}$ tela, são apresentadas as casas vazias e ordenadas e, abaixo, os cartões dos cachorrinhos desordenados. O jogo inicia com o telhado da casa $\mathrm{n}^{\mathbf{0}} \mathbf{1}$ "brilhando" enquanto o amigo virtual fala: "um". A criança deve clicar no cachorro com a numeração correspondente conduzindo-o até a casinha. Se conduzir o cachorro $\mathrm{n}^{\mathbf{0}} \mathbf{1}$, ele é encaixado, o seu telhado cessa de brilhar e o telhado da casa $\mathrm{n}^{\mathbf{0}} \mathbf{2}$ começa a brilhar para que o jogo prossiga. Caso contrário, o cachorro é rejeitado retornando à localização original e o telhado da casa $\mathrm{n}^{\circ} \mathbf{1}$ permanece brilhando. O jogo prossegue até que todos os cachorros entrem em suas casas. Ao final, o amigo virtual vira cambalhotas na tela, ou dá giros na cadeira de rodas, convidando o jogador para a segunda intervenção.

\section{$2^{\text {a }}$ Intrevenção: Jogo da Memória}

As casas permanecem ordenadas de 1 até 5 , e os cartões dos cachorros são retirados das casas, ficando dispostos abaixo das mesmas e são virados pelo amigo virtual, ficando todos com o verso da mesma cor. A criança clica nos cartões dos cachorros para embaralhá-los, com a ajuda do amigo virtual. O jogo prossegue com a mesma estrutura do anterior: $O$ telhado da primeira casa "brilha" e o amigo virtual fala: "um", e a criança clica um dos cartões desvirando-o. Se desvirar o n ${ }^{\circ}$ correto deve clicálo encaixando-o na casinha. Se desvirar outro número, o amigo virtual vira o cartão na mesma posição e a criança procura desvirar outro cachorro. Nesta versão, os cachorros precisam ser guardados seguindo a ordem numérica, explícita na brilho dos telhados. 
Caso a criança desvire um cartão que não corresponde ao telhado que está brilhando, ao encaixá-lo noutra casa, mesmo que corresponda ao $\mathrm{n}^{\circ}$ do cartão, ela o rejeitará. Ao final do jogo o amigo virtual faz peripécias convidando a criança para o jogo com o dado.

\section{$3^{\text {a }}$ Intervenção: Jogo com o Dado}

As casas são dispostas ordenadamente e os cachorros são retirados das casinhas e embaralhados, porém todos ficam virados de frente. A criança lança o dado, o amigo virtual canta $o \mathrm{n}^{\circ}$ sorteado e a criança clica o cachorro correspondente. Se acertar $\mathrm{o}$ encaixe, o telhado da casinha brilha, se não fizer a correspondência numérica, o cachorro é rejeitado e o amigo virtual, com as mãos na cintura, diz que não foi assim que combinaram a regra do jogo. A criança lança novamente o dado, seguindo o mesmo procedimento até que todos os cachorros sejam encaixados. Ao final, surgem cinco potes de ossos numerados dispostos desordenadamente na frente das casinhas, e a criança é convidada a realizar novamente o jogo com o dado. Nesta versão, acertando a correspondência, o cachorrinho sacode o rabinho e late.

\section{- Conclusões}

A mediação digital permite sem dúvida nenhuma, múltiplas formas de interação com o sujeito da aprendizagem. A possibilidade de se poder realizar com o computador diversos experimentos, permite à criança inúmeras oportunidades para a construção do saber através da sua ação e reflexão. $\mathrm{O}$ avanço da tecnologia digital, permitindo o re-uso de cenas, imagens, sons, simulações, textos, etc, tem proporcionado, de maneira bastante efetiva, a criação de muitas situações de aprendizagem, o que certamente, vem a ser mais uma alternativa a disposição do educador.

A utilização de uma ferramenta lúdica através da mediação digital, como o jogo dos cachorrinhos em desenvolvimento, além de atuar propositivamente à construção do número pela criança, permitirá verificar alguns efeitos dessa mediação.

Outro aspecto importante que se apreende deste experimento é o sua característica altamente multidisciplinar. O planejamento e produção de situações de aprendizagem que envolvem artefatos tecnológicos, apoia-se na existência de múltiplos saberes: pedagogia, psicologia, computação, matemática, etc. Esta característica multidisciplinar, se torna estes experimentos mais complexos, os torna certamente mais ricos e efetivos.

\section{- Bibliografia}

DELVAL, Juan. Introdução à Prática do MÉTODO CLíNICO. Descobrindo o pensamento das crianças, ArtMed Editora, 2002

FERREIRA, Luis de França. Condições para o Fazer e Compreender na Realidade Virtual. Tese de doutorado. Pós-Graduação em Informática na Educação. UFRGS. PortoAlegre, 2003.

FLAVELL, John. A Psicologia do Desenvolvimento de Jean Piaget, Livraria Pioneira Editora, São Paulo, 1996. 
LEARNING Systems Architeture Lab. SCORM Best Practices Guide for Content Developers. Carnigie Mellon University. Disponível em: http://www.lsal.cmu.edu/l sal/expertise/projects/developersguide/ acessado em $06 / 12 / 2004$.

LTSC. Learning technology standards committee website [On-line]. Disponível em: http://ltsc.ieee.org/, acessado em 06/12/2004.

LÜDKE, Menga; ANDRÉ, Marli E. D. A. Pesquisa em Educação: Abordagens qualitativas, Editora Pedagógica e Universitária Ltda, 1986.

MELLON, Carnegie. SCORM Best Practices for Content Developers. Learning Systems Laboratory. http://www.lsal.cmu.edu/lsal/expertise/projects/ developersguide/, acessado em 10/12/2004.

PIAGET, Jean. Biologia e Conhecimento, Editora Vozes, Petrópolis, 1996.

PIAGET, Jean. O Desenvolvimento do Pensamento, Equilibração das Estruturas Cognitivas, Publicações Dom Quixote, Lisboa, 1977.

RANGEL, Ana Cristina Souza. Educação matemática e a construção do número pela criança: uma experiência em diferentes contextos sócio-econômicos, Artes Médicas, 1992. 